\title{
Persistent Oligoarticular Juvenile Idiopathic Arthritis
}

National Cancer Institute

\section{Source}

National Cancer Institute. Persistent Oligoarticular Juvenile Idiopathic Arthritis. NCI

Thesaurus. Code C119040.

Oligoarticular juvenile idiopathic arthritis that never involves more than four separate joints after six months. 